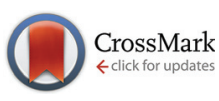

Cite this: Food Funct., 2015, 6, 1035

\title{
Microencapsulation of bioactives for food applications $\dagger$
}

\author{
Maria Inês Dias, ${ }^{a, b}$ Isabel C. F. R. Ferreira*a and Maria Filomena Barreiro*b
}

Health issues are an emerging concern to the world population, and therefore the food industry is searching for novel food products containing health-promoting bioactive compounds, with little or no synthetic ingredients. However, there are some challenges in the development of functional foods, particularly in which the direct use of some bioactives is involved. They can show problems of instability, react with other food matrix ingredients or present strong odour and/or flavours. In this context, microencapsulation emerges as a potential approach to overcome these problems and, additionally, to provide controlled or targeted delivery or release. This work intends to contribute to the field of functional food development by performing a comprehensive review on the microencapsulation methods and materials, the bioactives used (extracts and isolated compounds) and the final application development. Although several studies dealing with microencapsulation of bioactives exist, they are mainly focused on the process development and the majority lack proof of concept for final applications. These factors, together with the lack of regulation, in Europe and in the United States, delay the development of new functional foods and, consequently, their market entry. In conclusion, the potential of microencapsulation to protect bioactive compounds ensuring their bioavailability is shown, but further studies are required, considering both its applicability and incentives by regulatory agencies.

Received 19th December 2014 , Accepted 7th February 2015

DOI: 10.1039/c4fo01175a www.rsc.org/foodfunction reviews), was only observed from the second half of the 1990s, indicating an increasing tendency (Fig. 1). The exponential growth of patents and scientific research articles/reviews observed since 2005 was accompanied by the regulation (EC) no. 1924/2006 publication by the European Parliament on nutrition and health claims in foods, which was completed and finalized in 2011 by the European Food Safety Authority (EFSA) regarding beneficial health claims in certain food ingredients. ${ }^{2,3}$ In the United States (US) the regulation of functional foods is facilitated, as the food industry itself provides the product definition that will be placed on the market; food companies are only obliged to follow labelling and safety rules implemented by the Food and Drug Administration (FDA). ${ }^{4}$

Nowadays, consumers' awareness of health issues is growing together with the increasing incidence of chronic agerelated diseases, such as neurodegenerative diseases, diabetes and cancer, usually correlated with the lifestyle and dietary habits of our societies. ${ }^{5}$ Moreover, as the life expectancy is rising, with the consequent increase of health care costs, pharmaceutical and food industries have started to consider functional foods as a new market with huge growth potential. Nowadays, Japan, the United States (US) and the European Union (EU) are the leading markets for functional foods, representing in total $90 \%$ of the world market supply for this type of product. $^{6}$ In 2006, US and EU markets were valued at 33 billion US\$ and at 15 billion USS, respectively, with a 


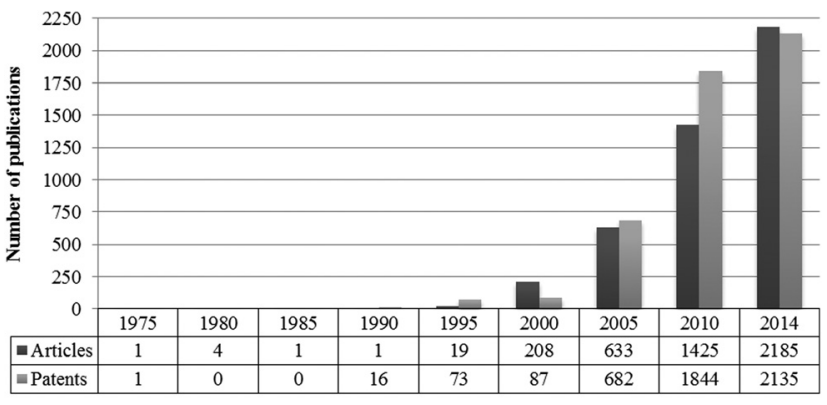

Year

Fig. 1 Number of research articles and reviews, and patents published in the period from 1970 to 2014 regarding functional foods (obtained on web of science, October 2014; keyword: functional food).

tendency to grow. Germany, France, the United Kingdom and the Netherlands are considered the most important countries within the European functional food market. ${ }^{7}$

\subsection{The problems related to the use of free bioactives}

Despite the known beneficial health effects of natural bioactive matrices and isolated individual compounds, as will be discussed in this section, they show some fragility that has to be considered regarding their direct use or incorporation into foods.

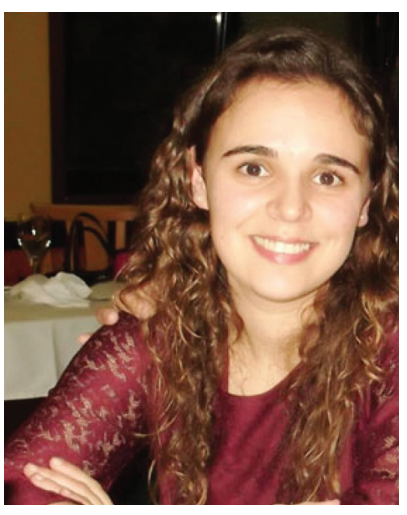

Maria Inês Dias
Maria Inês Dias has been a PhD student at Mountain Research Centre (CIMO) of the Polytechnic Institute of Bragança, REQUIMTE and Laboratory of Separation Reaction Engineering (LSRE) of the University of Porto since 2013. She obtained her degree in Biotechnological Engineering in 2009 and her Master's degree in Biotechnology in 2011, both at Polytechnic Institute of Bragança. Her main research interests are improvement of secondary metabolite production through in vitro culture techniques, chemical characterization and bioactive properties of edible plants, and microencapsulation of phenolic fractions.
The main factors limiting the use of bioactives in food applications are shown in Fig. 2. Bioactive ingredients are generally prone to degradation, both during storage and food processing, as many of them are physically, chemically and/or enzymatically unstable leading to their degradation or transformation with the consequent loss of bioactivity. In many cases the mechanism involved in the degradation of these bioactive molecules is very complex and still unknown. ${ }^{5,8} \mathrm{Wu}$ et $a l .{ }^{9}$ reported the reduction of the anthocyanin content in blackberry fruits after six months of canned and jam storage and also after drying treatment. Various types of cereals (wheat, barley and oat) were also tested for the content of biologically active compounds, such as tocopherols, phenolic compounds and microelements, and after hydrothermal processing, the concentration of these molecules severely decreased. ${ }^{10}$ Rawson et al. ${ }^{11}$ described major losses of bioactive compounds after processing exotic fruits such as mangoes, açai, pineapple and pitanga, subjecting them to heat treatments, pasteurization and drying, canning and even to storage processing steps. All these processes affect, to a lesser or greater extent, the stability, chemical characteristics, concentration, and even antioxidant activity of a number of compounds such as vitamins and phenolic compounds. Another study that describes the modifications occurring in fruits and vegetables during the processing steps was published by Nicoli

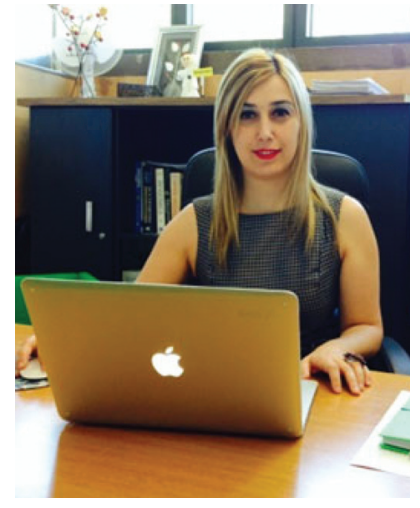

Isabel C.F.R. Ferreira
Isabel C.F.R. Ferreira is Coordinator Professor at Polytechnic Institute of Bragança (Portugal). She is a member of the Board of Directors of the Mountain Research Centre (CIMO) and the principal investigator of the Food Safety and Technology Group. She is an associate editor of Food \& Function (a journal of the Royal Society of Chemistry). She obtained her degree in Biochemistry (1996) at the University of Porto, Master's in Sciences (1999), PhD in Sciences-Chemistry (2003), and habilitation in Sciences-Chemistry (2011) at the University of Minho (Portugal). She is the principal investigator of several financed research projects, and an evaluator of international and national research projects, post-doc and PhD grants. She had supervised several post-doc, PhD and master's students in the BioChemCore group. She has received awards from several different organizations such as Calouste Gulbenkian Foundation. She has published over 260 papers in refereed journals and is a highly cited scientist (top 1\%) in Agricultural Sciences (Researcher ID: E-85002013; ORCID ID: 0000-0003-4910-4882; SCOPUS ID: 7102135224). Her main research interests are nutraceuticals and functional foods, chemistry of natural matrices/products, and emerging technologies for conservation of food matrices. 


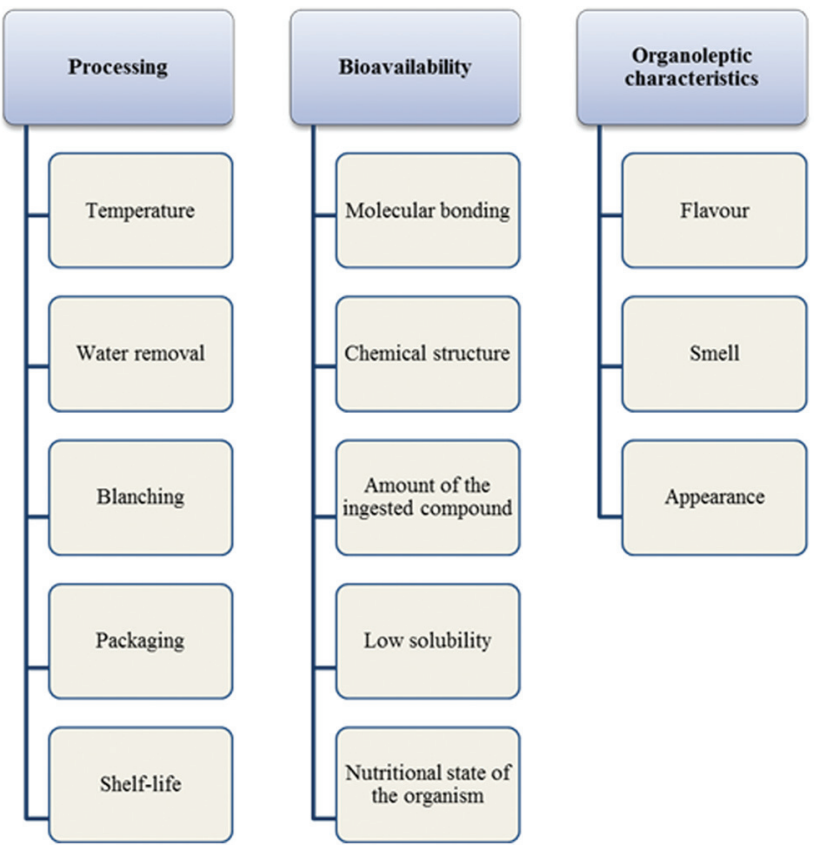

Fig. 2 Limiting factors for the use of free bioactives in food applications.

et al. ${ }^{12}$ focusing on the antioxidant activity decrease of the food matrix due to the loss and transformation of the antioxidant compounds, and also due to their interaction with other molecules. The processing steps of a food matrix involve the action of endogenous enzymes, water activity, oxygen pressure and also thermal/mechanical energy, and all of these factors can influence the degradation/transformation of the bioactive molecules leading to the loss of their intended characteristics.

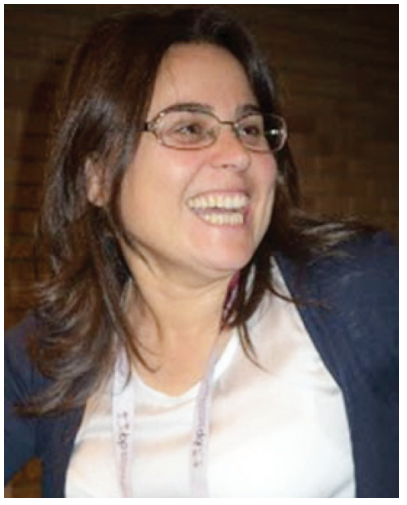

Maria Filomena Barreiro
Filomena Barreiro graduated in Chemical Engineering in 1990 at the Faculty of Engineering, University of Porto (FEUP). In 2000, she obtained her Ph.D. also at FEUP. She joined the Polytechnic Institute of Bragança (IPB, http:// www.ipb.pt) in 1995 where she is Coordinator Professor at the Chemical and Biological Department (DTQB). Since 2000 she has been a member of the research staff of the Laboratory of Separation and Reaction Engineering (LSRE, http://lsre.fe.up.pt/) (Researcher ID: L-98022014; ORCID ID: 0000-0002-6844-333X; SCOPUS ID: 23093315700). Her main research interests are synthesis and characterization of polymeric materials with special emphasis on materials from renewable resources and polyurethane chemistry, functional coatings and microencapsulation applied to different industrial fields.
Nevertheless, not all the compounds are equally affected; phenolic compounds and vitamins (e.g. vitamins $\mathrm{C}$ and $\mathrm{E}$ ) are more sensitive to blanching and long-term freezing treatments than minerals or dietary fibres. ${ }^{13}$ Despite the processing steps, the perishability of food is also a limitation in their intake in the free form. This is because the shelf life determines whether a particular food maintains its characteristics and bioactive properties. For instance, edible mushrooms have a very short shelf life and the postharvest changes, such as browning, cap transformation, texture and weight loss changes, occur immediately, which decrease their bioactive components. ${ }^{14}$

The ingested amount of the bioactive compound, its structure and chemical form, its interaction with other molecules, and also the organism itself (mucosal mass, intestinal and gastric behaviour, metabolism and protein bonding) will influence the stability and functionality within the human body, and consequently its bioavailability. ${ }^{15,16}$ For instance, phenolic compounds present very low bioavailability due to their poor solubility and stability, especially those with high molecular weight. Furthermore, there are no reports on specific receptors on the small intestinal epithelial cell surface, and thus the transport mechanism involves active diffusion and active efflux, lowering the permeability of such compounds. ${ }^{17}$ In the case of anthocyanins, they are very sensitive to $\mathrm{pH}$ and temperature changes in the medium. ${ }^{18}$ Concerning carotenoid compounds, the nature of the food matrix, the particle size and the processing method, and also their interaction with other food constituents, will affect their bioavailability; moreover, fibre constituents decrease the absorption of carotenoids. The nutritional state of the organism itself will influence the absorption of these molecules (e.g., protein deficiency affects the bioavailability). ${ }^{19,20}$ As an example, the interaction of mineral elements with other molecules can decrease their bioavailability, as is the case of calcium where compounds such as oxalates, tannins and dietary fibres decrease its absorption due to precipitation. ${ }^{21}$ Also, the gastrointestinal environment and epithelial transport can decrease the bioavailability of natural extracts, as described by Vermaak et al. ${ }^{22}$ who investigated the biological activity of green tea and sage extracts under simulated gastrointestinal conditions; the authors observed an accentuated decrease in the antimicrobial activity. Lipophilic compounds have also low solubility, which restricts their incorporation into many food matrices, especially in water-based carriers. The molecular weight, functionality and polarity seriously influence their solubility, physical state, chemical stability and bioavailability. ${ }^{8,23}$ It is very difficult to evaluate the bioavailability of these types of compounds, since once metabolized they reach the systemic circulatory system where they can be stored, utilized or excreted. Depending on the concentration and time of these molecules in a particular tissue, or their use in some biological function, the bioavailability can be estimated. ${ }^{24}$ For instance, the bioavailability of lycopene, a highly lipophilic carotenoid compound, is influenced dramatically by the intestinal lymphatic uptake. Faisal et al. ${ }^{25}$ applied an in vivo model to increase its solubility using digestible lipid excipients. A similar study was 
performed by Balakrishnan et $a .^{26}$ in order to increase the solubility and bioavailability of the Coenzyme $\mathrm{Q}_{10}$, practically insoluble in aqueous medium, by using oil and surfactant compounds for its oral delivery.

Another factor that drives researchers to invest their knowledge into the design of novel food delivery systems is the organoleptic behaviour of some bioactive extracts/compounds. They can present unpleasant taste, odour and/or textures. This is a crucial point for the food industry when developing a new product because the consumer gives importance not only to the price, but also to the taste, smell and appearance. Accordingly, consumers will choose the non-functional counterpart of a similar product, even if it has lower bioactive properties. ${ }^{16,27}$ It is known that many people avoid eating fruits and vegetables because most of their compounds such as polyphenols, terpenes and glucosinolates have bitter or astringent taste, making them unappealing to the consumer. ${ }^{28}$

To overcome the problems related to the direct use of bioactive extracts/compounds, microencapsulation techniques arise as a potential approach in the food industry to deal with their incorporation, either to impart additional functional properties or to protect the bioactive component itself.

The main goal of the present review is to highlight the use of microencapsulation techniques for food applications, as well as to discuss the advantages of microencapsulating bioactive extracts/compounds. Various extracts and compounds that have been encapsulated using different techniques and formulations will be enumerated focusing on the potential for functional food development. A particular emphasis will be given to examples where the final application (incorporation into food matrices) is explored.

\section{Overview of microencapsulation techniques and materials}

\subsection{The advantages of using microencapsulated bioactives}

Microencapsulation can provide a tool to protect natural extracts and compounds from the action of biotic, abiotic, and biological factors. It emerges as a reliable methodology not only for the food industry, but also for the fields of nutrition and health, where the stability, efficacy and bioavailability of these extracts and compounds are needed. As described previously, there are several factors affecting the bioactives' stability in their free form (Fig. 2), however with microencapsulation technology protection from factors such as light, moisture, heat and oxygen is provided. Also, the organoleptic characteristics of many food products can be masked, but most importantly functional/biological characteristics can be maintained after ingestion together with controlled release in a specific target. The success of a delivery system based on microencapsulation can be measured by the bioactives' behaviour during food processing and storage, and after ingestion. ${ }^{8}$

From a practical point of view, microencapsulation techniques protect the core material from the outside environment; it increases the product shelf life by reducing the transfer between the core and the surrounding medium, and by protecting the molecules from reaction with other food constituents, which can decrease their bioavailability. ${ }^{29}$ It also increases the solubility, dispersibility and flow of the bioactives. $^{30}$

Depending on the applied technology and encapsulated bioactive, the response of the produced delivery system will be different; each compound has specific characteristics that should be considered in the design of a novel microcapsulation process. For instance, phenolic compounds are very powerful antioxidant molecules; however they present problems in their bioavailability because they are transformed, after ingestion, into methylated, glucuronated and sulphated metabolites. ${ }^{31}$ Nano- and microparticle based delivery systems appear as a response to overcome these problems, increasing the phytochemical absorption of phenolic compounds in epithelial cells. ${ }^{17,32}$ In particular, Davidov-Pardo \& McClements ${ }^{33}$ showed that the microencapsulation of resveratrol increased its bioavailability.

Essential oils have also some organoleptic related problems, most of them presenting an unpleasant taste and odour, with very poor water solubility and high volatility. All these limitations can be overcome by using microencapsulation techniques that increase the effectiveness of their biological functions and decrease the sensory impact on food products. $^{34}$

\subsection{Microencapsulation techniques}

The microencapsulation concept was primarily developed by the pharmaceutical industrial sector, whose goal was to control and/or modify the release of drug substances. Nowadays, it still represents the major field using microencapsulation $(68 \%)$ while the food sector accounts for only $13 \%{ }^{35}$ The amount of scientific reports and patents regarding microencapsulation for food purposes (Fig. 3) is indicative of the growing interest in this technique regarding the incorporation of bioactive extracts and compounds. Nevertheless, the absence of regulation for novel food ingredients, including the ones derived from using nano- and micro-technologies in their preparation, is still remaining. In the USA the FDA is currently developing a recognition program for nanomaterials to overcome the existing scarcity of information, and also to assess food safety of these new ingredients. ${ }^{36}$ The introduction of microencapsulation technologies into the food industry allows the incorporation of flavouring agents in certain types of foods, and also the improvement of their functional and health properties. ${ }^{30,37}$ Regarding food science and biotechnology, the incorporation of natural ingredients intends to stabilize, protect and preserve the bioactives into a core, surrounded by a wall, or dispersed in a matrix, made of a material chosen to be suitable for the target delivery system. ${ }^{34}$ There have already been reviews on microencapsulation of bioactive compounds and extracts for food applications, ${ }^{29,30,34,37-40}$ nevertheless they mainly explored the available techniques for microencapsulation, lacking specificity in the existing examples of microencapsulated bioactive extracts and com- 


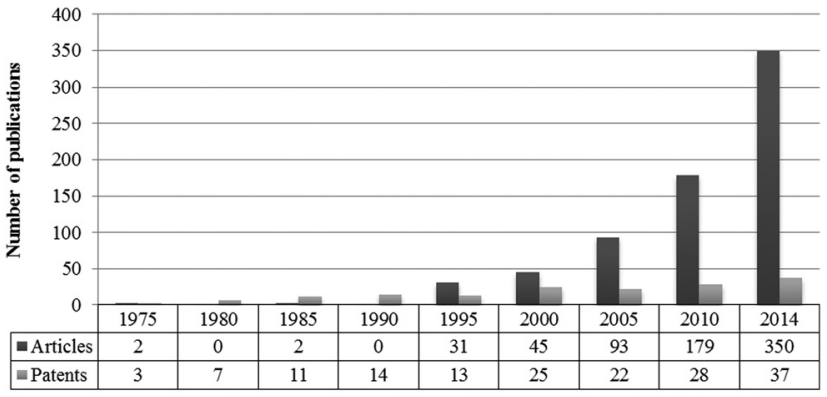

Year

Fig. 3 Number of research articles and reviews, and patents published in the period from 1970 to 2014 regarding microencapsulation for food purposes (obtained on web of science, October 2014; keywords: microencapsulation and food).

pounds together with the applicability of the performed studies. Fig. 4 shows the logical chain, from the choice of bioactives, materials and microencapsulation process to final applications evidencing the crucial points involved in each step.

Microcapsules are particles with diameters ranging from 1 to 1000 micrometers. The most common morphology is of two types: (1) shell type, where the core, the bioactive component itself or a carrier containing it (compounds that facilitate the release) is protected by a membrane; (2) matrix type, where the bioactive component is dispersed in a material's matrix. The encapsulation materials, production process, final morphology and ultimate application are the most important factors to be taken into account when designing a novel delivery system based product. Also, the stability and functional properties of the bioactive component must be taken into account when selecting the microencapsulation technique. Furthermore, to achieve high encapsulation yields it is necessary to ensure process reproducibility, release profile and overcome limiting drawbacks such as microsphere aggregation and adherence. ${ }^{30}$

The encapsulation methods and materials most commonly used in food applications are described in Tables 1 and 2, respectively (as also in the ESI $\dagger$ ). The definition of categories presented in Table 1 was somehow difficult because the microencapsulation processes can be categorized according to the formation mechanism, the consolidation method, and even according to the specific equipment used. A clear distinction among the described possibilities is not always clear in the published work. Therefore, in this work, efforts were made to define categories according to the microcapsule formation process and a set of general categories are proposed: coacervation, extrusion-based processes, spray-based processes, emulsion-based processes, liposomes, supercritical fluid based processes, ultrasound-based processes and others.

2.2.1. Spray-based process. Spray-based processes are by far the most common methods being divided into spraydrying, electrospray, spray-coagulation (according to internal or external gelation) and spray-freeze drying methods. Spraydrying, the oldest microencapsulation process used by the food industry, is a very straightforward technique. It can be described as flexible, allowing continuous production, making it a cost effective process and consequently the most economical among several encapsulation methods. It can be easily industrialized in terms of equipment and materials, which have a low cost compared with other available techniques. ${ }^{41}$ The most commonly used shell materials in this technique are carbohydrates which may limit the encapsulation of some bioactives. ${ }^{39}$ It produces high quality microcapsules, with a size less than $40 \mu \mathrm{m}$, by atomizing a liquid solution or emulsion through a nozzle to a hot gas chamber giving rise to the prompt formation of a powder. The method's speed and effectiveness ensure the production of microbiologically stable products, with lower costs and specific properties. ${ }^{37,41}$ There are several applications dealing with the encapsulation of bioactive compounds and extracts by spray-drying. Examples in the published literature are crude extracts, ${ }^{42-52}$ carotenoids, ${ }^{53,54}$ enzymes, ${ }^{55,56}$ essential oils, ${ }^{57-62}$ fatty acids, ${ }^{63-66}$ phenolic compounds (including anthocyanins) ${ }^{67-87}$ and vitamins. ${ }^{88}$ It is also noticeable (ESI $\dagger$ ) that the vast majority of the used shell materials, as was previously reported, are carbo-

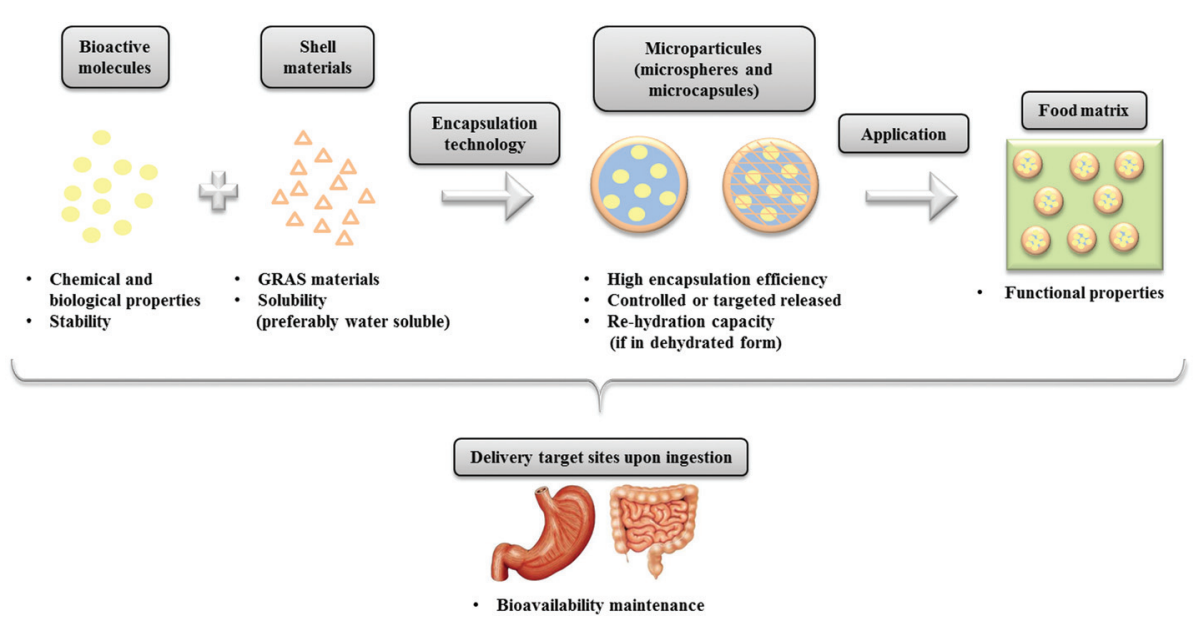

Fig. 4 Schematic procedures for the development of microencapsulation protocols (GRAS-generally recognized as safe). 
Table 1 The encapsulation methodologies mostly used for food applications, and the corresponding examples

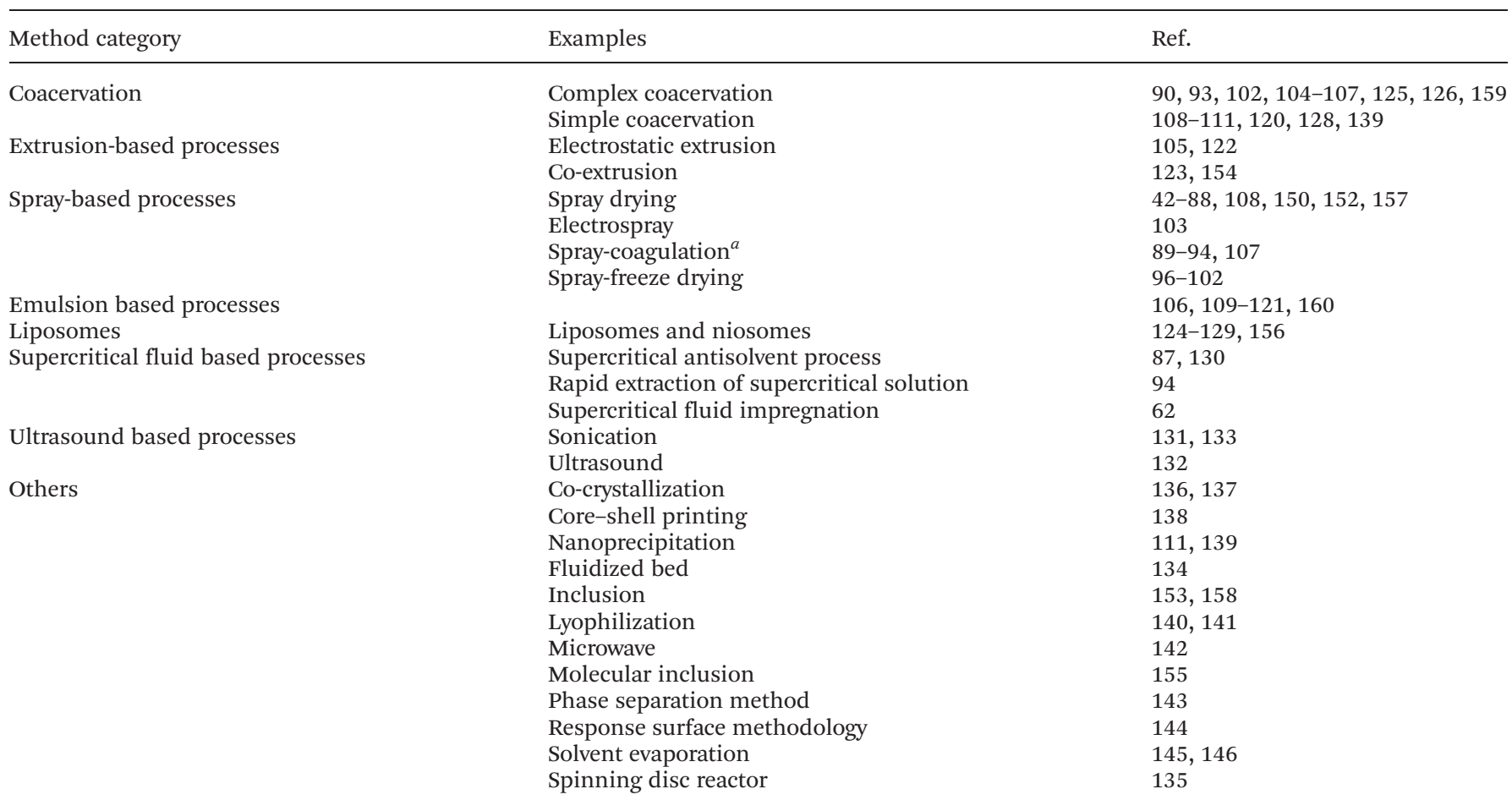

${ }^{a}$ Coagulation mostly achieved with internal or external gelation.

Table 2 Main materials used for encapsulating bioactive extracts and compounds for food applications (based on Kuang et al. ${ }^{30}$ )

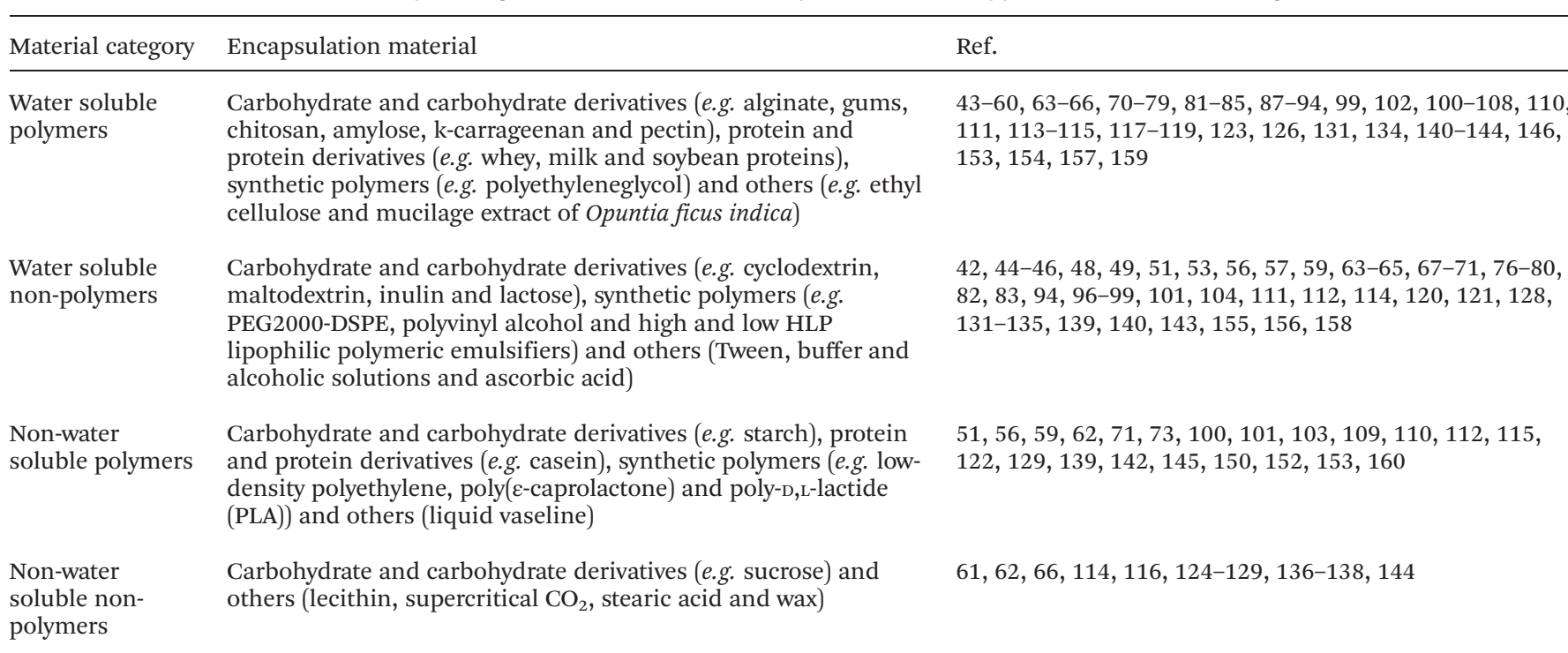

hydrates and derivatives. However, Medina-Torres et $a .^{72}$ encapsulated gallic acid in mucilage obtained directly from Opuntia ficus indica, while Cortés-Rojas et al. ${ }^{61}$ encapsulated eugenol in lipid formulations, both affording good results and high encapsulation yields. These results show the constant evolution of this method, and the possibility to overcome constraints related to the limited number of available shell materials, as stated by Gouin et al. ${ }^{39}$
Coagulation processes are also commonly used to encapsulate bioactive extracts and compounds for food applications, the most common being those based on alginate beads. ${ }^{89-94}$ Alginate beads are formed from the polyanionic copolymer derived from the brown marine algae, alginate, which is frequently used as a stabilizer and thickener of many food products. Its coagulation can be promoted by external gelation (e.g. using calcium chloride as the calcium source added to the 
coagulation solution) or internal gelation (e.g. using calcium carbonate as the calcium source added to the alginate solution). In the first case, gelation occurs mainly at the particle surface and in the second case gelation occurs mainly inside the formed particles. The formed materials, due to their degree of ionic reticulation and functionality, allow the control of water intake and thus the release of the bioactive component. ${ }^{95}$ The preparation of such alginate beads is easily performed at the lab-scale, and they have been used to encapsulate a wide variety of compounds (hydrophilic, lipophilic, oils among others), and the controlled release is achieved by $\mathrm{pH}$ changes. ${ }^{39,95}$

Freeze-drying technology allows the encapsulation of many food constituents, being used on a daily basis to stabilize compounds and increase controlled release. ${ }^{39}$ It is mostly used to encapsulate bioactive extracts, ${ }^{96}$ phenolic compounds, ${ }^{97-99}$ vitamin $\mathrm{C}^{100,101}$ and even essential oils. ${ }^{102}$ To the best of our knowledge the use of electrospray technology for food applications is not very common and only one work was found in the reviewed literature. ${ }^{103}$ This work refers to the encapsulation of folic acid (vitamin $\mathrm{B}_{9}$ ), and according to the provided description, it is a very appealing technology since the use of organic solvents and high temperatures is not required.

2.2.2. Coacervation. Coacervation is the second most commonly used encapsulation technique for food applications, not only because it provides high encapsulation efficiency, but also due to the triggered controlled release that can be based on the temperature, mechanical or biological mechanisms, providing the needed versatility to support the development of a wide range of food products. ${ }^{39}$ It can be divided into complex and simple coacervation; the first is based on the complexation of two oppositely charged polymers that form a strong polymeric shell or matrix. ${ }^{104}$ For the complex coacervation, chitosan is the preferable wall material, and alginate is the most commonly used polymer in all the mentioned studies. ${ }^{92,93,105-107}$ Chitosan has low toxicity, antimicrobial activity, and biocompatibility, but it is mainly muco-adherence that allows transmucosal absorption and better release of the bioactives. ${ }^{107}$ In simple coacervation the initially soluble polymer is precipitated by changing the $\mathrm{pH}$ or temperature. ${ }^{34}$ Milk proteins ${ }^{108,109}$ and pectins with PGPR (polyglycerol polyricinoleate $)^{110}$ are some examples of wall materials used in simple coacervation.

2.2.3. Emulsion based process. Emulsion based processes are also commonly used for food encapsulation applications. It allows the encapsulation of both water and oil soluble food ingredients. ${ }^{34,37}$ Emulsion based techniques have been successfully used to encapsulate bioactive compounds including fatty acids, ${ }^{111,112}$ vitamins,${ }^{113}$ phenolic compounds, ${ }^{109,114-117}$ anthocyanins, ${ }^{110-118}$ oils ${ }^{119,120}$ and bioactive extracts. ${ }^{106,121}$ This technique is sometimes coupled with a second one, in most cases a spray-drying based process, which gives rise to a dry powder that can be promptly introduced into a food matrix. ${ }^{37}$ In fact, several of the commonly used encapsulation processes start with the first step comprising the preparation of an emulsion. This is the reason why a straightforward divi- sion of the encapsulation techniques is not easy to achieve and some superimposition exists. In this work, and given the importance of spray-based processes, the cases dealing with emulsion coupled with spray techniques were included in the spray-based process category.

2.2.4. Extrusion based process. Extrusion methodologies, unlike the above described methods, are not so usual. They can be divided into electrostatic extrusion and co-extrusion. The extrusion method comprises the passage of the polymer melt with the solubilized bioactive through a nozzle, or the polymer melt and bioactive through concentric nozzles, leading to the formation of particles with high density and encapsulation efficiency. ${ }^{30,37}$ This technique is primarily used for the encapsulation of volatiles and unstable flavours. ${ }^{39}$ Belščak-Cvitanović et $a l^{105}$ and Barbosa-Pereira et al. ${ }^{122}$ demonstrated the efficiency of this method for the encapsulation of phenolic compounds. Co-extrusion is used to prepare spherical microbeads with a hydrophobic core, ${ }^{37}$ nevertheless it can also be used for the encapsulation of hydrophilic compounds in alginate beads as was done by Piazza \& Roversi. ${ }^{123}$

2.2.5. Liposomes. Liposome technology has been mostly used in pharmaceutical and cosmetic fields, for targeted delivery of therapeutic agents and inclusion of stabilizers in creams and lotions, respectively. For food applicability they represent a highly valuable resource due to their high encapsulation efficiency, stability and easy production. ${ }^{39}$ Foremost, liposomes have been used to stabilize and increase the bioavailability of bioactive molecules. ${ }^{124-127}$ Moreover it is widely used to encapsulate compounds that are poorly soluble in certain solvents. Coimbra et al. ${ }^{128}$ demonstrated the efficacy of liposomes for the encapsulation of resveratrol, caffeic acid, carvacrol, among others (compounds poorly soluble in water), while Rasti et al. ${ }^{129}$ increased the oxidative stability of polyunsaturated fatty acids by means of their encapsulation in liposomes.

2.2.6. Supercritical fluid based process. Supercritical fluid based processes have many advantages for the encapsulation of sensitive substances such as essential oils or enzymes, always being coupled with other encapsulation techniques. Almeida et $a l .{ }^{62}$ used a supercritical fluid impregnation technique to encapsulate oregano essential oil into a starch matrix, achieving a homogeneous product in a faster way due to the low viscosity and higher diffusion of supercritical $\mathrm{CO}_{2}$. On the other hand, Santos et al. ${ }^{94}$ by using rapid extraction of a supercritical solution and Sosa et al. ${ }^{130}$ and Visentin et al. ${ }^{87}$ by using a supercritical antisolvent process applied this technique to encapsulate bioactive extracts with high encapsulation efficiencies. The main advantages of supercritical fluids are related to their physical properties such as viscosity, density, solvating power, diffusion and mass transfer. The solubilisation of the core and shell materials is therefore faster as microcapsule formation is facilitated, i.e. they are formed by using lower temperatures and in the absence of water. ${ }^{39}$

2.2.7. Ultrasound based process. Ultrasound based processes, such as sonication and ultrasound, are also reliable techniques for food applications, mostly being used with the double functions of extracting the bioactives and forming the 
microcapsules. ${ }^{131,132}$ However, Kalogeropoulos et al. ${ }^{133}$ used sonication to aggregate the inclusion complex of propolis extract and $\beta$-cyclodextrins to form microcapsules.

2.2.8. Others. Despite all those described above, there are other methods not so common for food applications. An example is the fluidized bed, a microencapsulation technique for powder compounds. It needs the preparation of a suspension with the coating material (polysaccharides, proteins, emulsifiers and fats) and subsequent spraying, offering a more effective controlled release of the core material than with other existing technologies. ${ }^{30,37,39}$ Li et al. ${ }^{134}$ used this technology achieving good integrity and stability of the core compound after the drying process. Molecular inclusion is another process that is not so commonly used, generally referred to as a supramolecular method in the sense that the bonding between the encapsulated compound and the shell material occurs in a cavity-bearing substrate by hydrogen bonds, van der Waals forces or entropy-driven hydrophobic effects. Cyclodextrins and hydrophobic vitamins are the most commonly used shell materials in molecular inclusion methods. ${ }^{39}$ Spinning-disk and centrifugal co-extrusion are new atomisation methods, possibly used in modified spray encapsulation methods; the difference lies in the formation of the capsule, involving the creation of a film with much smaller dimensions than those obtained in common atomisers. ${ }^{39}$ Akhtar et al. ${ }^{135}$ showed the reduction of the particle size using a spinning-disk reactor to encapsulate flavonoids by means of a double emulsion technique, achieving better stabilization of the prepared emulsions by this technique. Other microencapsulation methods that are not commonly used in the food sector are cocrystallization, ${ }^{136,137}$ core-shell printing, ${ }^{138}$ nanoprecipitation, ${ }^{111,139}$ lyophilisation, ${ }^{140,141}$ microwave, ${ }^{142}$ phase separation methods, ${ }^{143}$ response surface methodology ${ }^{144}$ and solvent evaporation methods. ${ }^{145,146}$

\subsection{Encapsulation materials}

When designing an experiment protocol for the development of encapsulated products (Fig. 4), the shell material choice is one of the most important steps, firstly because it has to be non-toxic to the organism, its preparation should consider environmental issues and use clean solvents (water soluble materials are therefore preferable) and, finally, because it plays a crucial role in the bioactive release behaviour. Conditions such as $\mathrm{pH}$, temperature, salts and ion concentration also have to be taken into account and defined in accordance with the ultimate objective of the developed microcapsules. In this work the materials were divided into four categories (Table 2), according to Kuang et al. ${ }^{30}$ which discriminate them as water and non-water soluble materials, and as polymer and nonpolymer materials. Within each category it was also possible to sub-divide them into carbohydrate and its derivatives, protein and its derivatives, synthetic polymers and other types of materials.

The coating material and its physical structure strongly influence the product development; nevertheless there are some constraints since law does not allow the application of some materials in food. They must be considered "generally recognized as safe" (GRAS), biodegradable and efficient as the protective barrier between the nucleus and the surrounding medium. Both EU through the EFSA and the US through FDA have many strict rules about material usage for food applications. $^{37,147}$ The most commonly used materials are carbohydrate polymers (starch and cellulose and their derivatives), plant exudates and extracts (gum, galactomannans, pectins and soybean polysaccharide), marine extracts (carrageenan and alginate), microbial and animal derived polysaccharides (xanthan, gellan, dextran and chitosan), and also proteins, lipids and others (paraffin and some inorganic materials). ${ }^{148}$ This is in accordance with our survey, where it can be observed that water soluble materials, both polymer (e.g. alginate and chitosan) and non-polymer (e.g. cyclodextrins) types, are the most commonly used, followed by non-water soluble polymers (e.g. starch and casein) and, finally, non-water soluble nonpolymers (e.g. sucrose and lecithin).

Concerning the EU, no access is provided to a list of authorized materials for food product development by EFSA. There is a lack of information, as the existing list is under construction. They include only food additives and nutrient sources, listing only those who are not considered food additives (e.g. starch), but without any reference to whether they are authorized or not. ${ }^{149}$ Regarding the US, the FDA has a list of approved food ingredients that allows the companies and academia to design microencapsulation protocols more suitable to serve food industry purposes. Despite the above listed compounds, identified as the most commonly used, not all have been approved by the FDA (or they were not considered for review or the assessment is pending). From Table 2, and following the guidelines of FDA, it can be observed that the approved materials are stearic acid, sucrose, amylopectin, maize starch, calcium caseinate, casein, FHCO (fully hydrogenized canola oil), PGPR, $\beta$-cyclodextrin, ethanol, lactose, PEG (polyethylene glycol), alginate, chitosan, whey protein, cellulose, xanthan, ethyl cellulose, soy protein, inulin, pectin and lysozyme. The materials with pending requests for assessment are lecithin, caffeine, arabic gum, milk proteins and poloxamers. For the remaining materials no information is available. It is also necessary to understand that some investigations are conducted to find new encapsulation materials, meaning that although they are not currently present in the FDA list, they could be added in the future. Many of them are of natural origin such as starch from Araucaria angustifolia (Bertol.) Kuntze seeds, ${ }^{100,101}$ mucilage extract from Opuntia ficus Indica $^{72}$ and gelatinized sweet potato starch, ${ }^{150}$ and therefore further studies are needed to establish the safety of these materials.

\section{Incorporation of microencapsulated bioactives in food matrices}

\subsection{Bioactive extracts}

The main reason to consider a bioactive extract is related to synergistic effects occurring among their components that 
often result in increased bioactive characteristics. The information regarding microencapsulated bioactive extracts obtained from different plant materials and other natural matrices after extraction with various solvents is summarized in Table 3. Crude extracts represent a significant part of the microencapsulation studies, followed by polyphenols (as also anthocyanins), essential oils, vitamins, proteins and fat extracts.

The majority of the microencapsulation studies for food purposes have focused on the technique development itself which includes the definition of the best suitable materials and the achievement of microcapsules with the adequate morphology, encapsulation efficiency, stability and release behaviour. The studies calling up the development of final applications, i.e. the test of the microencapsulated materials with real food matrices, are much scarcer. Chiou \& Langrish $^{47}$ used the crude extract (water) of Hibiscus sabdariffa L. for encapsulation with the fibres extracted from the same fruit as the wall material, aiming at developing a novel nutraceutical product using a by-product usually not consumed. A similar study conducted by Berg et $a .^{70}$ in which pectin (natural polysaccharide) was used as the encapsulation wall material to protect anthocyanins extracted from Vaccinium genus fruits showed that the addition of gelling substances provided a higher encapsulation efficiency. The optimization of encapsulation methodologies is constantly evolving, as is the case of supercritical fluid-based processes, which were used to encapsulate green tea extract from Camellia sinensis L. leaves with polycaprolactone (PCL), by high pressure antisolvent coprecipitation demonstrating high retention of catechins in the co-precipitates, and also to encapsulate ethanolic extracts from Rosmarinus officinalis L. leaves with poloxamer polymers, with similar results. ${ }^{87,130}$ With a different goal, but intending to improve encapsulation and delivery of bioactive extracts, Averina \& Allémann ${ }^{111}$ developed $\mathrm{pH}$ sensitive micro- and nanoparticle containing natural sources of polyunsaturated fatty acids, namely oils extracted from Thymallus baikalensis Dybowski muscle and Pinus sibirica Du Tour seeds, and commercial fish oil, by using the emulsification-diffusion and nanoprecipitation techniques with promising results. Barras et al. ${ }^{124}$ developed lipid nanoparticles loaded with polyphenol extracts to enhance their solubility and stability. Many of the studies with phenolic compounds are performed with the main objective to optimize the encapsulation process, ${ }^{80,118,125,131}$ using different types of extracts (e.g. alcoholic, aqueous, hydroalcoholic etc.). In fact, there is no specific standard protocols for the extraction of each class of phenolic compounds, depending on the nature of the sample and the objective of the work (structure elucidation and quantification). ${ }^{151}$ In terms of proteins, ${ }^{138,152}$ vitamins, ${ }^{88}$ phytosterols $^{153}$ and essential oils, ${ }^{57,59,60}$ the majority of the studies was also conducted with the aim of developing new encapsulating methodologies and materials, and optimizing the process.

After optimization of the encapsulation process, it is necessary to establish whether the extracts maintain, reduce or increase their bioactive characteristics. Therefore, several bioactivity assays can be conducted to evaluate the antioxidant and antimicrobial activities, and quantify total phenolic compounds. To assess the antioxidant activity, the DPPH $(2,2-$ diphenyl-1-picrylhydrazyl) scavenging activity is the most commonly used assay not only to characterize a given sample, but also to evaluate the bioactivity maintenance. The studies performed by López-Córdoba et al. ${ }^{136}$ and Chan et al. ${ }^{154}$ with crude extracts of Ilex paraguariensis A. St. Hil. aerial parts and Piper sarmentosum Roxb., respectively, showed that encapsulation did not affect, positively or negatively, the antioxidant activity of the extracts. On the other hand, in the studies conducted by Igual et al. ${ }^{49}$ and Parthasarathi et al. ${ }^{43}$ with Solanum quitoense L. pulp and Garcinia cowa Roxb. fruit, respectively, the encapsulation proved to be very effective, since an increase in the antioxidant activity of the extracts was observed, which can be explained by protection of the bioactives from degradation. Anthocyanin extracts obtained from Garcinia indica Choisy fruit pulp, ${ }^{68}$ Euterpe oleracea Mart. fruit pulp ${ }^{71}$ and Daucus carota L. roots ${ }^{67}$ were encapsulated with maltodextrins, which proved to be efficient in protecting these extracts whose stability and antioxidant activity increased after microencapsulation. With another goal Deladino et al. ${ }^{90}$ used the DPPH assay to assess the diffusion and kinetic behaviour of the produced microencapsulated system. The oxygen radical absorbance capacity (ORAC), 2,2'-azino-bis(3-ethylbenzothiazoline6-sulphonic acid assay (ABTS) and trolox equivalent antioxidant capacity (TEAC) assays have also been used to evaluate the antioxidant activity of microencapsulated extracts..$^{50,62,76,82,105,115,117}$ As previously mentioned, the quantification of phenolic compounds is also a very common methodology to assess the effectiveness of the encapsulation process. $^{42,44,46,48,64,78,79,85,92,98,141,155}$ Some studies also describe the use of carotenoids to infer the efficacy of the microencapsulation process. ${ }^{94,141}$

Antibacterial and antifungal properties are among the most studied and important bioactivities not only due to the increasing resistance of the microorganisms to commercially available synthetic antibiotics, but also because natural matrices present great potential for the discovery of new drugs. There are several studies focusing on the microencapsulation of natural extracts presenting antibacterial and antifungal activities. Sansone et $a l .{ }^{52}$ and Fernandes et al. $^{45}$ reported the antifungal activity of Paeonia rockii (S.G. Haw \& Lauener) roots and Lippia sidoides Cham. leaves, respectively, showing the advantage of their microencapsulation and enhancement of the antifungal activity was obtained compared with the extracts in the free form. The antibacterial activity of the essential oil extracted from Citrus hydrix D.C. fruit skins was assessed by Adamiec et al.,$^{58}$ also reporting the enhancement of the activity in the microencapsulated extract. Souza et al. ${ }^{86}$ studied the antimicrobial effect of Vitis labrusca L. ethanolwater (67.6\%) encapsulated extract, showing a very good growth inhibiting capacity of Staphylococcus aureus and Listeria monocytogenes.

Studies considering the improvement of bone quality in rats ${ }^{121}$ and in vitro cytotoxicity ${ }^{107}$ were performed with micro- 
Table 3 Microencapsulated bioactive extracts

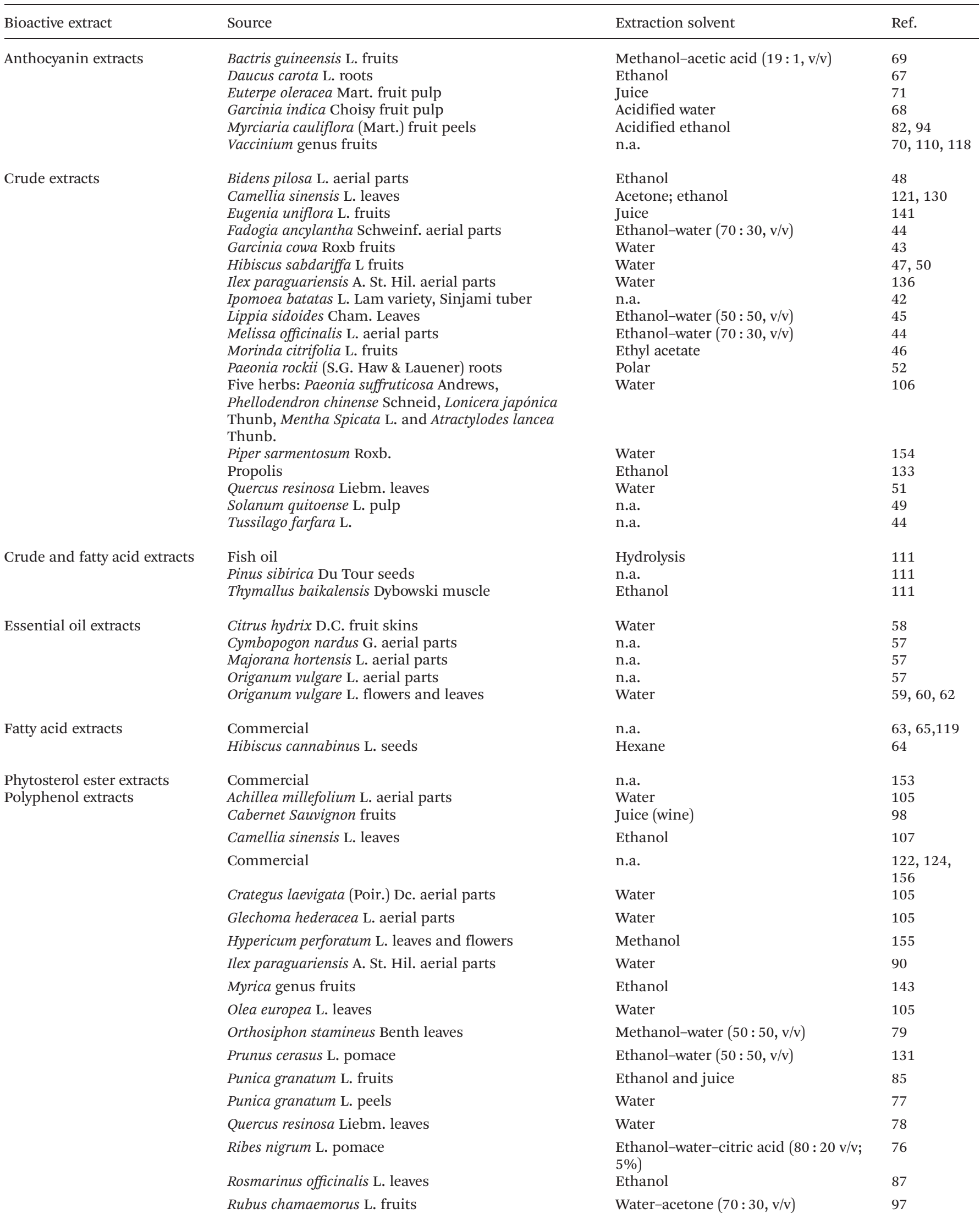


Table 3 (Contd.)

\begin{tabular}{|c|c|c|c|}
\hline & Rubus idaeus L. leaves & Water & 105 \\
\hline & Urtica dioica $\mathrm{L}$. leaves & Water & 105 \\
\hline & Vaccinium myrtillus $\mathrm{L}$. fruits & n.a. & 117 \\
\hline & Vitis labrusca L. seeds and fruits & Water-ethanol $(67.6: 32.4, \mathrm{v} / \mathrm{v})$ & 86 \\
\hline $\begin{array}{l}\text { Polyphenol and betalain } \\
\text { extracts }\end{array}$ & Opuntia ficus-indica fruits & Juice and ethanol & 80 \\
\hline Polyphenol and oil extracts & Commercial & n.a. & 128 \\
\hline Protein extracts & Commercial & n.a. & 138 \\
\hline Oil extracts & Commercial & n.a. & 120,150 \\
\hline
\end{tabular}

encapsulated $C$. sinensis tea. The antioxidant $\alpha$-glucosidase inhibitory activity of microencapsulated aqueous extracts from Punica granatum L. peel and the anti-inflammatory effect of commercial polyphenols and oil extracts were also studied. ${ }^{77,128}$

As can be observed in Fig. 4, in vitro release studies are among the most important steps to consider when developing and validating a microencapsulated product. A successful microencapsulated system not only has to protect the bioactive compound ensuring its bioavailability, but also needs to guarantee the intended release behaviour (temporal and target oriented). In vitro release studies can be performed by simulating the gastrointestinal environment using $\mathrm{pH}$ buffers mimicking the conditions of digestion, ${ }^{106,156}$ or using in vitro gastrointestinal models comprising enzymes and $\mathrm{pH}$ buffers. ${ }^{110,133,143,150}$ Tavano et al. ${ }^{156}$ showed, by in vitro release studies, that curcumin and quercetin when microencapsulated in niosomes improved the solubility after gastrointestinal digestion. Frank et al. ${ }^{110}$ and Park et al. ${ }^{150}$ reported that after in vitro gastrointestinal digestion, microencapsulated anthocyanin extracts of $V$. myrtillus and a commercial oil extract, respectively, presented good resistance to $\mathrm{pH}$ change during digestion, being released only under intestinal conditions. This corroborates the efficacy of microencapsulation in designing adequate delivery systems for water and non-water soluble compounds to be incorporated in innovative food products.

\subsection{Bioactive compounds}

The importance of studying individual bioactive compounds lies in their powerful bioactivities, with different applications, such as in pharmaceutical and food industries. In this context their isolation from the original matrix is an interesting topic of study and provides an added value to the developed pro- ducts. A set of microencapsulated individual bioactive compounds used for food application purposes is described in Table 4 . The number of articles concerning the encapsulation of individual compounds is markedly lower than that for bioactive extracts. However, phenolic compounds are once again the individual molecules most commonly used in microencapsulation experiments. Most of these studies are focused on the development and optimization of microencapsulation techniques, ${ }^{74,82,132,140,144,145,157}$ including new encapsulation materials. An example is the work performed by MedinaTorres et al., ${ }^{72}$ in which commercial gallic acid was encapsulated using mucilage extracted from $O$. ficus Indica. Robert et $a .^{73}$ also encapsulated gallic acid using acetylated starch and inulin, obtaining higher encapsulation efficiency with the first material. On the other hand, for quercetin and vanillin phenolic compounds, inulin gave the best results. ${ }^{81}$ Despite the beneficial health effects of phenolic compounds, their stability and bioavailability are severely compromised during food processing, storage and digestion, as mentioned in the previous sections. So, microencapsulation of individual phenolic compounds could provide a way to maintain or increase their antioxidant activity, ${ }^{114,139}$ stability $^{75,97}$ and bioavailability. ${ }^{96,127}$ The antimicrobial activity was also tested in microcapsules containing chlorogenic acid isolated from Nicotiana tabacum L. leaves, indicating that its activity was not affected by microencapsulation, being an alternative in the development of food products with antimicrobial properties. ${ }^{158}$

Polyunsaturated fatty acids are also the target of microencapsulation studies. Their known beneficial health effects make them very appealing to enrich food matrices. However, their lipophilic nature and rancidity tendency are obstacles in the development of efficient delivery systems. Naik et al. ${ }^{102}$ developed an encapsulation technique for the delivery of 
Table 4 Microencapsulated individual bioactive compounds

\begin{tabular}{|c|c|c|c|}
\hline Class & Individual bioactive compounds & Source & Ref. \\
\hline \multirow[t]{3}{*}{ Carotenoids } & Curcumin & Commercial & $114,127,159$ \\
\hline & Lutein & Commercial & 104 \\
\hline & $\beta$-Carotene & Capsicum annuum $\mathrm{L}$. fruits & 53 \\
\hline Carotenoids and vitamins & Curcumin and retinol & Commercial & 109 \\
\hline \multirow[t]{2}{*}{ Essential oil } & Cardamom oleoresin & Commercial & 137 \\
\hline & Engenol and eugenyl acetate & Syzygium aromaticum $\mathrm{L}$. buds & 61 \\
\hline \multirow[t]{2}{*}{ Fatty acid } & $\alpha$-Linolenic acid & Lepidium sativum Linn. seeds & 102 \\
\hline & $\omega-3$ Fatty acids & Commercial & 66,129 \\
\hline & Gallic acid & Commercial & $72,73,140$ \\
\hline & Isoflavone & Commercial & 116 \\
\hline & Mangiferin & Mangifera indica L. bark & 74 \\
\hline & Naringenin and quercetin & Commercial & 75 \\
\hline & Quercetin & Commercial & 139 \\
\hline & Quercetin and vanillin & Commercial & 81 \\
\hline & Quercitrin & Albizia chinensis $\mathrm{L}$. flowers $(90: 10, \mathrm{v} / \mathrm{v})$ & 145 \\
\hline & Resveratrol & Arachis hypogaea L. sprout & 144 \\
\hline & Resveratrol & Polygonum cuspidatum Siebold \& Zucc roots & 132 \\
\hline & Rutin and anthocyanins & Hibiscus sabdariffa L. dried calyx & 135 \\
\hline \multirow[t]{2}{*}{ Proteins } & Albumin and hirudin & Commercial & 93 \\
\hline & Papain & Commercial & 91 \\
\hline & Glucose, vitamin B12, olive oil & Commercial & 103,146 \\
\hline & $\begin{array}{l}\text { Fish oil, phytosterols ( } 5 \alpha \text {-cholestane, } \beta \text {-sitosterol, } \\
\text { campesterol and stigmasterol) and limonene }\end{array}$ & Commercial & 89,113 \\
\hline
\end{tabular}

$\alpha$-linoleic acid isolated from the seeds of Lepidium sativum Linn. using freeze drying to achieve a stable and bioavailable compound. On the other hand, Shaw et al. ${ }^{66}$ and Rasti et al. ${ }^{129}$ developed different lipophilic delivery systems for commercial $\omega$-3-fatty acids. Shaw et $a .^{66}$ used the spray-drying technique with lecithin and chitosan as the wall material, to prevent lipid oxidation and to study the reconstruction of the enriched microcapsules in aqueous medium, showing that this multilayer system is very promising. Rasti et al. ${ }^{129}$ used liposome based delivery systems to microencapsulate $\omega$-3-fatty acids, using soybean phospholipids as the wall material. The authors demonstrated that the formation of liposomes in aqueous medium, combined with the antioxidant protection of the phospholipids, increased the stability and prevented fatty acid peroxidation. Other compounds, also very unstable and there- fore benefiting from microencapsulation, are essential oils or their constituents. In addition to the lipophilic character they are also very volatile, needing the protection by microencapsulation. Lipid carriers involve the formulation of a lipidic solution containing solid lipids, surfactants and drying carriers (e.g. polysaccharides) and have provided high encapsulation efficiencies for eugenol and eugenyl acetate isolated from Syzygium aromaticum L. buds. ${ }^{61}$ Microencapsulation by co-crystallization of cardamom oleoresin also protected their major components, 1,8-cineole and $\alpha$-terpinyl acetate; nevertheless, some degradation occurred during packaging and storage. ${ }^{137}$

Carotenoids are a family of compounds largely used for food coloration in place of synthetic dyes, presenting additionally antioxidant and antiangiogenic effects. Nevertheless, their tendency to oxidation and isomerization is high. Qv et al. ${ }^{104}$ 
and $\mathrm{Xu}$ et $a .^{159}$ studied the stability of lutein and curcumin, respectively, after microencapsulation by complex coacervation with Ca-alginate/k-carrageenan, and Ca-alginate/lysozyme, respectively. Both achieved good encapsulation efficiencies and demonstrated the efficacy of the used method. Spada et al. ${ }^{100,101}$ microencapsulated commercial $\beta$-carotene in starch obtained from Araucaria angustifolia (Bertol.) Kuntze seeds, and concluded that a modified gelation form of this starch led to higher carotenoid encapsulation efficiency ensuring protection against adverse conditions. Aissa et $a .^{54}$ tested microcapsules enriched with $\beta$-carotene for its genotoxic and antiangiogenic effects, using arabic gum as the wall material. The authors observed preservation of the genotoxic effects, but a decrease in antiangiogenic activity, maybe due to the loss of bioavailability during microencapsulation.

Organic acids, ${ }^{83,84,99,142}$ enzymes $^{55,56}$ and proteins ${ }^{91,93}$ are examples of other individual compounds that have been subjected to microencapsulation.

Vitamin $\mathrm{B}_{2}$ (riboflavin) and vitamin $\mathrm{B}_{9}$ (folic acid) have also been microencapsulated for food purposes. Due to their known beneficial health effects, coupled with a high tendency to degradation and loss of bioavailability, in vitro release tests were used to evaluate new delivery systems. Chen \& Subirade ${ }^{113}$ tested the release of riboflavin using simulated gastric, intestinal and pancreatic fluids, concluding that riboflavin microcapsules made of alginate/whey protein are semi-destroyed by the intestinal fluid and completely released with the pancreatic fluid. To estimate the product shelf life, Wichchukit et al. ${ }^{89}$ studied the release of riboflavin incorporated into a food product, a model beverage. Prasertmanakit et al. ${ }^{146}$ studied the in vitro release of folic acid from ethyl cellulose microcapsules, a material that had good encapsulation efficiency. The addition of a water soluble polymer, sucrose, caused swelling of the polymer matrix, which allowed better controlled release of folic acid.

An improvement in delivery system development is the encapsulation of a mixture of bioactive compounds within the same microcapsule, thereby obtaining several beneficial effects. Augustin et al. ${ }^{112}$ developed an oil-in-water emulsion to stabilize commercial fish oil, resveratrol and tributyrin using caseinate, glucose and starch, to study their behaviour in the gastrointestinal tract, obtaining increased bioavailability for all the compounds. Pan et al. ${ }^{109}$ studied the oxidative stability of curcumin (carotenoid) and retinol (essential oil) in oil-in-water emulsions, with very satisfactory results.

\subsection{Incorporation in food matrices}

Some examples of applicability studies with microencapsulated bioactive extracts or individual compounds are described in Table 5. After an exhaustive search in the literature, it was confirmed that the vast majority of the studies do not include the validation of the developed microencapsulated bioactives through their incorporation into food matrices. Only twelve studies were found where this final step, so important for the food industry, was included. In general, milk and dairy products such as cheese and yoghurt, and ice creams are the pre- ferable food matrices under study. The sector of cereals, bread and pasta, is also significant in applicability studies. Tea, soup and meat are also food matrices that have been tested for incorporation of bioactive microcapsules. Phenolic extracts of Punica granatum L. peels were studied by Çam et al. ${ }^{77}$ and were added to ice cream to enhance antioxidant and $\alpha$-glucosidase inhibitory activities. Martins et al. ${ }^{92}$ and Robert et al. ${ }^{85}$ also incorporated phenolic extracts in yogurt using Rubus ulmifolius Schott flowers and Punica granatum L. fruits, respectively. Martins et al. ${ }^{92}$ obtained a higher antioxidant activity in yogurt with microencapsulated extracts, compared with the use of extracts in the free form and with the control (yogurts without extracts); on the other hand, Robert et $a l .{ }^{85}$ also reported a higher content of phenolic compounds and anthocyanins in yogurt with microencapsulated extracts. The incorporation technique developed by Barbosa-Pereira et $a l^{122}$ to add phenolic extracts in active packaging to extend the shelf-life of meat products gave promising results retarding lipid oxidation and microbial growth. In terms of individual phenolic compounds, a water soluble isoflavone was microencapsulated in a polyglycerol monostearate emulsion and further incorporated in milk to study its stability during storage and after in vitro digestion. It was demonstrated that the microencapsulated isoflavone did not affect milk taste and that its absorption in the intestine increased. ${ }^{116}$

Citric acid and its derivative, (-)-hydroxycitric acid, were also used in incorporation studies; in particular, the derivative extracted from the fruits of Garcinia cowa Roxb. was incorporated into bread ${ }^{83,99}$ and pasta; ${ }^{84}$ in both cases, bread and pasta enriched with microencapsulated bioactives showed good sensory and quality attributes, which proves the viability of using such strategies in food product development. Citric acid was also incorporated in chewing gum at a micronized scale, using a technique based on casein and inulin to form bioactive microcapsules, to develop chewing gums with health promoting properties. ${ }^{142}$ Soups, among the most highly consumed food products worldwide, also served as the matrix for the incorporation study developed by Rubilar et al. ${ }^{65}$ Microcapsules containing fatty acids (linseed oil) were added to an instant soup in powder form in order to develop a new functional product; moreover, since the linseed oil was microencapsulated in a polymeric matrix consisting of arabic gum and maltodextrin, a higher controlled release of the lipophilic core was successfully achieved. Sardar et al. ${ }^{137}$ also encapsulated a lipophilic compound, cardamom oleoresin. Since the stability of this compound for spray-drying was very poor, a sucrose wall matrix was used with a co-crystallization method giving rise to small flavouring sugar cubes for tea beverages. The produced cubes were stable to storage when packed in a three-layer metalized laminate. Cheese, although appreciated by many consumers, is rich in fat and, therefore, there have been efforts for the addition of vegetable oils to this matrix. However, oils degrade very quickly, benefiting from the addition of antioxidants such as vitamins $\mathrm{A}$ and $\mathrm{E}$ and coenzymes. In this context, the work of Stratulat et al. ${ }^{160}$ was intended to inhibit lipid peroxidation (rancidity), by formulat- 
Table 5 Examples of studies with microencapsulated bioactive extracts or individual compounds incorporated in food matrices

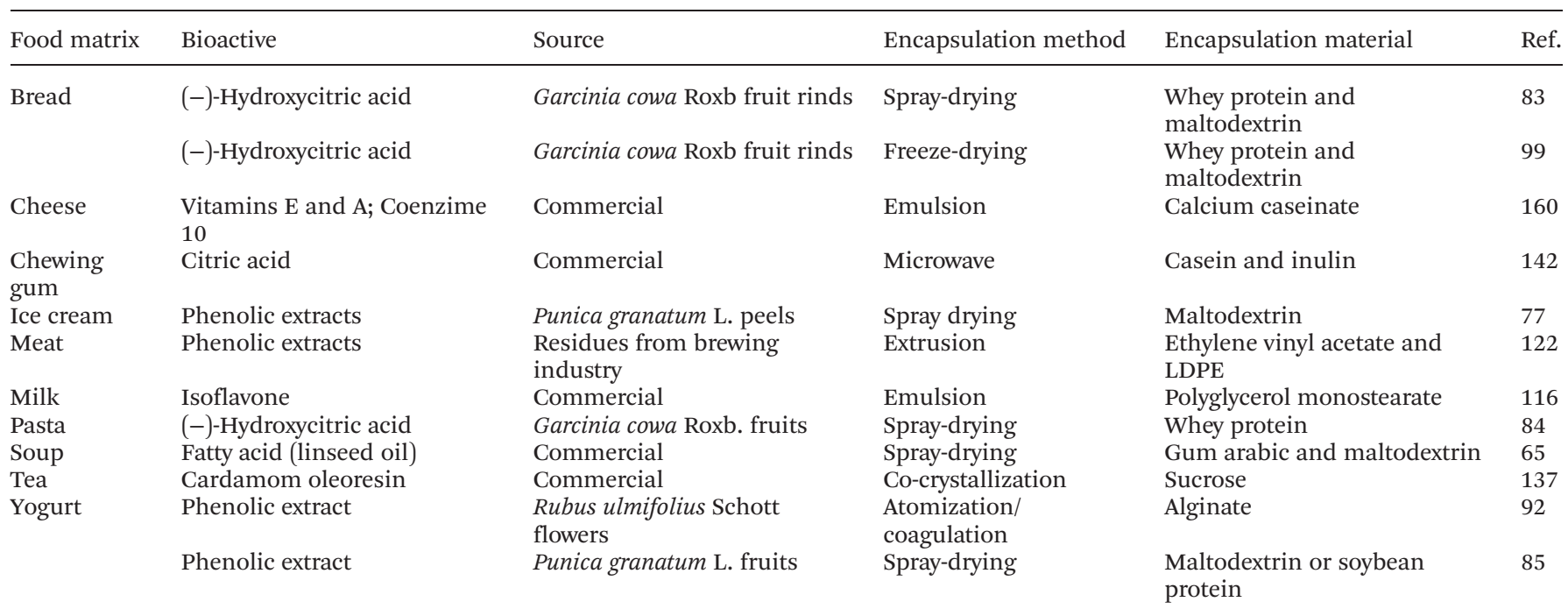

ing emulsions, stabilized with calcium caseinate, containing vitamins A and E, and Coenzyme Q10. The results showed that the vegetables oils did not affect the cheese stability, due to the presence of antioxidants.

\section{Conclusion}

Nowadays, food not only serves to satisfy the primal urge of hunger but is also intended to overcome dietary flaws and/or impart health benefits. Bioactives are sources of functional molecules with recognized health effects in populations that otherwise would not be able to benefit from them. Nevertheless, they show organoleptic constraints and instability to food processes, storage and ingestion, which has led to research in the field of bioactive protection and controlled release. Among the proposed technologies, microencapsulation emerged as a viable route to valorise natural bioactives in functional foods, thus extending their benefits to a wider population.

According to the present review, there are several examples available of microencapsulation of bioactives using a wide range of processes and encapsulating materials. Among the various possibilities, the spray-based processes, e.g. spraydrying, are the most commonly used techniques. The advantages are its easy implementation, namely at the industrial level, and the fact of being inexpensive. Nevertheless, green techniques, such as supercritical and ultrasound based processes, are nowadays attracting much attention.

Water soluble materials, both polymer and non-polymer ones, are the most commonly used encapsulation materials. They include carbohydrate polymers (starch and cellulose and their derivatives), plant exudates and extracts (gum, galactomannans and pectins), marine extracts (carrageenan and alginate), and microbial and animal derived polysaccharides (xanthan, gellan, dextran and chitosan). In most of the cases, the industrial applicability in the field of food production is prevented by current regulations.

Crude and phenolic extracts, together with individual phenolic compounds, are the most studied bioactives for food purposes. Nevertheless, studies dealing with final food applications are scarce, demanding investment from academia, industry and regulatory agencies. Finally, the consumers also have a crucial role in the acceptance of new products in the market.

\section{Acknowledgements}

The authors are grateful to Fundação para a Ciência e a Tecnologia (FCT, Portugal) for financial support to CIMO (strategic project PEst-OE/AGR/UI0690/2011) and LSRE (PEst-C/EQB/ LA0020/2011), and M. I. Dias grant (SFRH/BD/84485/2012). Financial support from QREN, ON2 and FEDER (NORTE-070124-FEDER-000014) is also acknowledged.

\section{Notes and references}

1 J. A. Mílner, Am. J. Clin. Nutr., 2010, 7, 1654-1659.

2 European Parliament, Regulation (EC) No. 1924/2006, 2006.

3 EFSA, Regulation (EC) No. 1924/2006, 2006.

4 FDA, Guide to nutrition labeling and education act (NLEA) requirements, 1994.

5 J. C. Espín, M. T. Carcía-Conesa and F. A. TomásBarberán, Phytochemistry, 2007, 68, 2986-3008.

6 B. Bigliardia and F. Galati, Trends Food Sci. Technol., 2013, 31, 118-129.

7 I. Siró, E. Kápolna, B. Kápolna and A. Lugasi, Appetite, 2008, 51, 456-467. 
8 I. J. Joye, G. Davidov-Pardo and D. J. McClements, Trends Food Sci. Technol., 2014, 40, 1-15.

9 R. Wu, B. Frei, J. A. Kennedy and Y. Zhao, LWT-Food Sci. Technol., 2010, 43, 1253-1264.

$10 \mathrm{H}$. Zielinski, H. Kozłowska and B. Lewczuk, Innovative Food Sci. Emerging Technol., 2001, 2, 159-169.

11 A. Rawson, A. Patras, B. K. Tiwari, F. Noci, T. Koutchma and N. Brunton, Food Res. Int., 2011, 44, 1875-1887.

12 M. C. Nicoli, M. Anese and M. Parpinel, Trends Food Sci. Technol., 1999, 10, 94-100.

13 R. Puupponen-Pimiä, S. T. Häkkinen, M. Aarni, T. Suortti, A. Lampi, M. Eurola, V. Piironen, A. M. Nuutila and K. Oksman-Caldentey, J. Sci. Food Agric., 2003, 83, 13891402.

14 A. Fernandes, A. L. Antonio, M. B. P. P. Oliveira, A. Martins and I. C. F. R. Ferreira, Food Chem., 2012, 135, 641-650.

15 B. Holst and G. Williamson, Curr. Opin. Biotechnol., 2008, 19, 73-82.

16 S. Y. Leong and I. Oey, Food Chem., 2012, 133, 15771578.

17 Z. Li, H. Jiang, C. Xu and L. Gu, Food Hydrocolloids, 2015, 43, 153-164.

18 I. Fernandes, A. Faria, C. Calhau, V. Freitas and N. Mateus, J. Funct. Foods, 2014, 7, 54-66.

19 D. B. Rodriguez-Amaya, J. Food Compos. Anal., 2010, 23, 726-740.

20 E. Fernández-García, I. Carvajal-Lérida, M. Jarén-Galán, J. Garrido-Fernández, A. Pérez-Gálvez and D. HorneroMéndez, Food Res. Int., 2012, 46, 438-450.

21 A. Amalraj and A. Pius, Food Chem., 2015, 170, 430-436.

22 I. Vermaak, A. M. Viljoen, J. H. Hamman and S. F. V. Vuuren, Phytochem. Lett., 2010, 2, 166-170.

23 D. J. McClements, E. A. Decker and J. Weiss, J. Food Sci., 2007, 72, 109-124.

24 D. J. McClements and Y. Li, Adv. Colloid Interface Sci., 2010, 159, 213-228.

25 W. Faisal, T. Ruane-O'Hora, C. M. O'Driscoll and B. T. Griffin, Int. J. Pharm., 2013, 453, 307-314.

26 P. Balakrishnan, B. Lee, D. H. Oh, J. O. Kim, Y. Lee, D. Kim, J. Jee, Y. Lee, J. S. Woo, C. S. Yong and H. Choi, Int. J. Pharm., 2010, 374, 66-72.

27 T. Bech-Larsen and J. Scholderer, Trends Food Sci. Technol., 2007, 18, 231-234.

28 A. Drewnowski and C. Gomez-Carneros, Am. J. Clin. Nutr., 2000, 72, 1424-1435.

29 Z. Fang and B. Bhandari, Trends Food Sci. Technol., 2010, 21, 510-523.

30 S. S. Kuang, J. C. Oliveira and A. M. Crean, Crit. Rev. Food Sci. Nutr., 2010, 50, 951-968.

31 S. Heleno, A. Martins, M. J. R. P. Queiroz and I. C. F. R. Ferreira, Food Chem., 2015, 173, 501-513.

32 S. Wang, R. Su, S. Nie, M. Sun, J. Zhang, D. Wu and N. Moustaid-Moussa, J. Nutr. Biochem., 2014, 25, 363-376.

33 G. Davidov-Pardo and D. J. McClements, Trends Food Sci. Technol., 2014, 38, 88-103.
34 F. Nazzaro, P. Orlando, F. Fratianni and R. Coppola, Curr. Opin. Biotechnol., 2012, 23, 182-186.

35 I. M. Martins, M. F. Barreiro, M. Coelho and A. E. Rodrigues, Chem. Eng. J., 2014, 245, 191-200.

36 H.-S. Kwak, Nano- and Microencapsulation for Foods, John Wiley \& Sons, United Kingdom, 2014.

37 V. Nedovic, A. Kalusevic, V. Manojlovic, S. Levic and B. Bugarski, Procedia Food Sci., 2011, 1, 1806-1815.

38 P. M. M. Schrooyen, R. van der Meer and C. G. De Kruif, Proc. Nutr. Soc., 2001, 60, 475-479.

39 S. Gouin, Trends Food Sci. Technol., 2004, 15, 330347.

40 C. P. Champagne and P. Fustier, Curr. Opin. Biotechnol, 2007, 18, 184-190.

41 A. Gharsallaoui, G. Roudaut, O. Chambin, A. Voilley and R. Saurel, Food Res. Int., 2007, 40, 1107-1121.

42 M. Ahmed, M. S. Akter, J. Lee and J. Eun, LWT-Food Sci. Technol., 2010, 43, 1307-1312.

43 S. Parthasarathi, P. N. Ezhilarasi, B. S. Jena and C. Anandharamakrishnan, Food Bioprod. Process., 2013, 9, 103-110.

44 F. Sansone, T. Mencherini, P. Picerno, M. d'Amore, R. P. Aquino and M. R. Lauro, J. Food Eng., 2011, 105, 468-476.

45 L. P. Fernandes, R. C. Candido and W. P. Oliveira, Food Bioprod. Process., 2012, 90, 425-432.

46 D. Krishnaiah, R. Sarbatly and R. Nithyanandam, Chem. Eng. Res. Des., 2012, 90, 622-632.

47 D. Chiou and T. A. G. Langrish, J. Food Eng., 2007, 82, 84-91.

48 D. F. Cortés-Rojas, C. R. F. Souza and W. P. Oliveira, Chem. Eng. Res. Des., 2015, 93, 366-376.

49 M. Igual, S. Ramires, L. H. Mosquera and N. MartínezNavarrete, Powder Technol., 2014, 256, 233-238.

50 T. A. G. Langrish and R. Premarajah, Adv. Powder Technol., 2013, 24, 771-779.

51 N. E. Rocha-Guzmán, J. A. Gallegos-Infante, R. A. González-Laredo, F. Harte, L. Medina-Torres, L. A. Ochoa-Martínez and M. Soto-García, J. Food Sci., 2010, 75, 57-61.

52 F. Sansone, P. Picerno, T. Mencherini, A. Porta, M. R. Lauro, P. Russo and R. P. Aquino, J. Food Eng., 2014, 120, 260-267.

53 A. Y. Guadarrama-Lezama, L. Dorantes-Alvarez, M. E. Jaramillo-Flores, C. Pérez-Alonso, K. Niranjan, G. F. Gutiérrez-López and L. Alamilla-Beltrán, J. Food Eng., 2012, 112, 29-37.

54 A. F. Aissa, M. L.P. Bianchi, J. C. Ribeiro, L. C. Hernandes, A. F. Faria, A. Z. Mercadante and L. M. G. Antunes, Food Chem. Toxicol., 2012, 50, 1418-1424.

55 M. Santa-Maria, H. Scher and T. Jeoh, J. Microencapsulation, 2012, 29, 286-295.

56 M. V. Bule, R. S. Singhal and J. F. Kennedy, Carbohydr. Polym., 2010, 82, 1290-1296.

57 R. Baranauskienė, R. R. Venskutonis, K. Dewettinck and R. Verhé, Food Res. Int, 2006, 39, 413-425. 
58 J. Adamiec, C. Borompichaichartkul, G. Srzednicki, W. Panket, S. Piriyapunsakul and J. Zhao, Dry. Technol., 2012, 30, 914-920.

59 J. M. G. Costa, S. V. Borges, A. A. C. T. Hijo, E. K. Silva, G. R. Marques, M. A. Cirillo and V. M. Azevedo, J. Microencapsulation, 2013, 30, 717-727.

60 L. C. Garcia, R. V. Tonon and M. D. Hubinger, Dry. Technol., 2012, 30, 1413-1421.

61 D. F. Cortés-Rojas, C. R. F. Souza and W. P. Oliveira, J. Food Eng., 2014, 127, 34-42.

62 A. P. Almeida, S. Rodríguez-Rojo, A. T. Serra, H. Vila-Real, A. L. Simplicio, I. Delgadilho, S. B. Costa, L. B. Costa, I. D. Nogueira and C. M. M. Duarte, Innovative Food. Sci. Emerging Technol., 2013, 20, 140-145.

63 G. Gallardo, L. Guida, V. Martinez, M. C. López, D. Bernhardt, R. Blasco, R. Pedroza-Islas and L. G. Hermida, Food Res. Int., 2013, 52, 473-482.

64 S. Ng, P. Wong, C. Tan, K. Long and K. Nyam, Eur. J. Lipid Sci. Technol., 2013, 115, 1309-1318.

65 M. Rubilar, E. Morales, K. Contreras, C. Ceballos, F. Acevedo, M. Villarroel and C. Shene, Eur. J. Lipid Sci. Technol., 2012, 114, 423-433.

66 L. A. Shaw, D. J. McClements and E. A. Decker, J. Agric. Food Chem., 2007, 55, 3112-3119.

67 S. Ersus and U. Yurdagel, J. Food Eng., 2007, 80, 805812.

68 C. A. Nayak and N. K. Rastogi, Dry. Technol., 2010, 28, 1396-1404.

69 C. Osorio, B. Acevedo, S. Hillebrand, J. Carriazo, P. Winterhalter and A. L. Morales, J. Agric. Food Chem., 2012, 58, 6977-6985.

70 S. Berg, M. Bretz, E. A. Hubbermann and K. Schwarz, J. Food Eng., 2012, 108, 158-165.

71 R. V. Tonon, C. Brabet and M. D. Hubinger, Food Res. Int., 2010, 43, 907-914.

72 L. Medina-Torres, E. E. García-Cruz, F. Calderas, R. F. G. Laredo, G. Sánchez-Olivares, J. A. GallegosInfante, N. E. Rocha-Guzmán and J. Rodríguez-Ramírez, LWT-Food Sci. Technol., 2013, 50, 642-650.

73 P. Robert, P. García, N. Reyes, J. Chávez and J. Santos, Food Chem., 2012, 134, 1-8.

74 J. R. R. Souza, J. P. A. Feitosa, N. P. S. Ricardo, M. T. S. Trevisan, H. C. B. Paula, C. M. Ulrich and R. W. Owen, Food Hydrocolloids, 2013, 33, 10-18.

75 F. Sansone, P. Picerno, T. Mencherini, F. Villecco, A. M. D'Ursi, R. P. Aquino and M. R. Lauro, J. Food Eng., 2011, 103, 188-196.

76 A. M. Bakowska-Barczak and P. P. Kolodziejczyk, Ind. Crops Prod., 2011, 34, 1301-1309.

77 M. Çam, N. C. İçyer and F. Erdoğan, LWT-Food Sci. Technol, 2014, 55, 117-123.

78 J. A. Gallegos-Infante, N. E. Rocha-Guzmán, R. B. González-Laredo, L. Medina-Torres, C. A. GomezAldap, L. A. Ochoa-Martínez, C. A. Martínez-Sánchez, B. A. Hernández-Santos and J. Rodríguez-Ramírez, Food Biosci., 2013, 2, 31-38.
79 S. F. Pang, M. M. Yusoff and J. Gimbun, Food Hydrocolloids, 2014, 37, 159-165.

80 C. Saénz, S. Tapia, J. Chávez and P. Robert, Food Chem., 2009, 114, 616-622.

81 D. Sun-Waterhouse, S. S. Wadhwa and G. I. N. Waterhouse, Food Bioprocess Technol., 2013, 6, 2376-2388.

82 P. I. Silva, P. C. Stringheta, R. F. Teófilo and I. R. N. Oliveira, J. Food Eng., 2013, 117, 538-544.

83 P. N. Ezhilarasi, D. Indrani, B. S. Jena and C. Anandharamakrishnana, J. Sci. Food Agric., 2013, 94, 1116-1123.

84 D. S. Pillai, B. Prabhasankar, B. S. Jena and C. Anandharamakrishnan, Int. J. Food Prop., 2012, 15, 590-604.

85 P. Robert, T. Gorena, N. Romero, E. Sepulveda, J. Chavez and C. Saenz, Int. J. Food Sci. Technol., 2010, 45, 13861394.

86 V. B. Souza, A. Fujita, M. Thomazini, E. R. Silva, J. F. Lucon Jr., M. I. Genovese and C. S. Favaro-Trindade, Food Chem., 2014, 164, 380-386.

87 A. Visentin, S. Rodríguez-Rojo, A. Navarrete, D. Maestri and M. J. Cocero, J. Food Eng., 2012, 109, 9-15.

88 A. Romo-Hualde, A. I. Yetano-Cunchillos, C. GonzálezFerrero, M. J. Sáiz-Abajo and C. J. González-Navarro, Food Chem., 2012, 133, 1045-1049.

89 S. Wichchukit, M. H. Oztop, M. J. McCarthy and K. L. McCarthy, Food Hydrocolloids, 2013, 33, 66-73.

90 L. Deladino, P. S. Anbinder, A. S. Navarro and M. N. Martino, Carbohydr. Polym., 2008, 71, 126-134.

91 D. Betancur-Ancona, J. Pacheco-Aguirre, A. CastellanosRuelas and L. Chel-Guerrero, Innovative Food. Sci. Emerging Technol, 2011, 12, 67-72.

92 A. Martins, L. Barros, A. M. Carvalho, C. Santos-Buelga, I. P. Fernandes, F. Barreiro and I. C. F. R. Ferreira, Food Funct., 2014, 5, 1091-1100.

93 T. Chandy, D. L. Mooradian and G. H. R. Rao, J. Appl. Polym. Sci., 1998, 70, 2143-2153.

94 D. T. Santos, J. Q. Albarelli, M. M. Beppu and M. Angela, Food Res. Int., 2013, 50, 617-624.

95 C. H. Goh, P. W. S. Heng and L. W. Chan, Carbohydr. Polym., 2012, 88, 1-12.

96 M. H. Jung, P. N. Seong, M. H. Kim, N. Myong and M. Chang, Nutr. Res. Pract., 2013, 7, 366-372.

97 P. Laine, P. Kylli, M. Heinonen and K. Jouppila, J. Agric. Food Chem., 2008, 56, 11251-11261.

98 V. Sanchez, R. Baeza, M. V. Galmarini, M. C. Zamora and J. Chirife, Food Bioprocess Technol., 2011, 6, 1350-1354.

99 P. N. Ezhilarasi, D. Indrani, B. S. Jena and C. Anandharamakrishnana, J. Food Eng., 2013, 117, 513520.

100 J. C. Spada, C. P. Z. Noreña, L. D. F. Marczak and I. C. Tessaro, Carbohydr. Polym., 2012, 89, 1166-1173.

101 J. C. Spada, L. D. F. Marczak, I. C. Tessaro and C. P. Z. Noreña, Int. J. Food Sci. Technol., 2012, 47, 186194. 
102 A. Naik, V. Meda and S. S. Lele, Eur. J. Lipid Sci. Technol., 2014, 116, 837-846.

103 R. Pérez-Masiá, R. López-Nicolás, M. J. Periago, G. Ros, J. M. Lagaron and A. López-Rubio, Food Chem., 2015, 168, 124-133.

104 X. Qv, Z. Zeng and J. Jiang, Food Hydrocolloids, 2011, 25, 1596-1603.

105 A. Belščak-Cvitanović, R. Stojanović, V. Manojlović, D. Komes, I. J. Cindrić, V. Nedović and B. Bugarski, Food Res. Int., 2011, 44, 1094-1101.

106 P. C. Hui, W. Wang, C. Kan, F. S. Ng, E. Wat, V. X. Zhang, C. Chan, C. B. Lau and P. Leung, Colloids Surf., B, 2013, 111, 156-161.

107 J. Liang, F. Li, Y. Fang, W. Yang, X. An, L. Zhao, Z. Xin, L. Cao and Q. Hu, Colloids Surf., B, 2011, 82, 297-301.

108 Q. Chen, D. McGillivray, J. Wen, F. Zhong and S. Y. Quek, J. Food Eng., 2013, 117, 505-512.

109 Y. Pan, R. V. Tikekar, M. S. Wang, R. J. Avena-Bustillos and N. Nitin, Food Hydrocolloids, 2014, 43, 1-9.

110 K. Frank, E. Walz, V. Gräf, R. Greiner, R. Köhler and H. P. Schuchmann, J. Food Sci., 2012, 77, 50-57.

111 E. Averina and E. Allémann, LWT-Food Sci. Technol., 2013, 53, 271-277.

112 M. A. Augustin, M. Y. Abeywardena, G. Patten, R. Head, T. Lockett, A. D. Luca and L. Sanguansri, J. Funct. Food, 2011, 3, 25-37.

113 L. Chen and M. Subirade, Biomaterials, 2006, 27, 46464654.

114 P. Malik, R. K. Ameta and M. Singh, Chem.-Biol. Interact., 2014, 222, 77-86.

115 J. L. Vidal, L. M. Avello, C. Loyola, P. J. Campos, M. P. Aqueveque, S. R. Dungan, L. M. Galotto and M. A. Guarda, Chil. J. Agric. Res., 2012, 73, 17-23.

116 J. S. Seok, J. S. Kim and H. S. Kwak, Arch. Pharmacal Res., 2003, 26, 426-431.

117 M. Betz, B. Steiner, M. Schantz, J. Oidtmann, K. Mäder, E. Richling and U. Kulozik, Food Res. Int., 2012, 47, 51-57.

118 M. Betz and U. Kulozik, Procedia Food Sci., 2011, 1, 20472056.

119 S. S. Gupta and M. Ghosh, J. Food Eng., 2014, 121, 64-72.

120 F. Ostertag, J. Weiss and D. J. McClements, J. Colloid Interface Sci., 2012, 388, 95-102.

121 L. Haidong, Y. Fang, T. Zhihong and R. Changle, Int. J. Biol. Macromol., 2011, 49, 561-566.

122 L. Barbosa-Pereira, I. Angulo, J. M. Lagarón, P. PaseiroLosada and J. M. Cruz, 2014, 26, 310-318.

123 L. Piazza and T. Roversi, Procedia Food Sci., 2011, 1, 13741380.

124 A. Barras, A. Mezzetti, A. Richard, S. Lazzaroni, S. Roux, P. Melnyk, D. Betbeder and N. Monfilliette-Dupont, Int. J. Pharm., 2009, 379, 270-277.

125 M. Gibis, K. Thellmann, C. Thongkaew and J. Weiss, Food Hydrocolloids, 2014, 41, 119-131.

126 S. Madrigal-Carballo, S. Lim, G. Rodriguez, A. O. Vila, C. G. Krueger, S. Gunasekaran and J. D. Reed, J. Funct. Foods, 2010, 2, 99-106.
127 M. Hasan, N. Belhaj, H. Benachour, M. Barberi-Heyob, C. J. F. Kahn, E. Jabbari, M. Lindera and E. Arab-Tehrany, Int. J. Pharm., 2014, 461, 519-528.

128 M. Coimbra, B. Isacchi, L. V. Bloois, J. S. Torano, A. Keta, X. Wu, F. Broere, J. M. Metselaar, C. J. F. Zijcken, G. Storm, R. Bilia and R. M. Schiffelers, Int. J. Pharm., 2011, 416, 433-442.

129 B. Rasti, S. Jinap, M. R. Mozafari and A. M. Yazid, Food Chem., 2012, 135, 2761-2770.

130 M. V. Sosa, S. Rodríguez-Rojo, F. Mattea, M. Cismondi and M. J. Cocero, J. Supercrit. Fluids, 2011, 56, 304311.

131 B. Cilek, A. Luca, V. Hasirci, S. Sahin and G. Sumnu, Eur. Food Res. Technol., 2012, 235, 587-596.

132 S. Mantegna, A. Binello, L. Boffa, M. Giorgis, C. Cena and G. Cravotto, Food Chem., 2012, 130, 746750.

133 N. Kalogeropoulos, S. Konteles, I. Mourtzinos, E. Troullidou, A. Chiou and V. T. Karathanos, J. Microencapsulation, 2009, 26, 603-613.

134 Y. Li, S. Xu and D. Sun, J. Food Eng., 2007, 83, 76-83.

135 M. Akhtar, B. S. Murray, E. I. Afeisume and S. H. Khew, Food Hydrocolloids, 2014, 34, 62-67.

136 A. López-Córdoba, L. Deladino, L. Agudelo-Mesa and M. Martino, J. Food Eng., 2014, 124, 158-165.

137 B. R. Sardar, K. M. Tarade and R. S. Singhal, J. Food Eng., 2013, 117, 530-537.

138 N. Blanco-Pascual, R. B. J. Koldeweij, R. S. A. Stevens, M. P. Montero, M. C. Gómez-Guillén and A. T. T. Cate, Food Bioprocess Technol., 2014, 7, 2472-2483.

139 T. Wu, F. Yen, L. Lin, T. Tsai, C. Lin and T. Cham, Int. J. Pharm., 2008, 346, 160-168.

140 C. G. Rosa, C. D. Borges, R. C. Zambiazi, M. R. Nunes, E. V. Benvenutti, S. R. Luza, R. F. D’Avila and J. K. Rutz, Ind. Crops Prod., 2013, 46, 138-146.

141 J. K. Rutz, R. C. Zambiazi, C. D. Borges, F. D. Krumreich, S. R. Luz, N. Hartwig and C. G. Rosa, Carbohydr. Polym., 2013, 98, 1256-1265.

142 S. Abbasi, S. Rahimi and M. Azizi, J. Microencapsulation, 2009, 26, 90-96.

143 L. Zheng, Z. Ding, M. Zhang and J. Sun, J. Food Eng., 2011, 104, 89-95.

144 Y. Lee, S. Ahn and H. Kwak, Food Hydrocolloids, 2013, 30, 307-314.

145 A. Kumari, S. K. Yadav, Y. B. Pakade, V. Kumar, B. Singh, A. Chaudhary and S. C. Yadav, Colloids Surf., B, 2010, 82, 224-232.

146 S. Prasertmanakit, N. Praphairaksit, W. Chiangthong and N. Muangsin, AAPS PharmSciTech, 2009, 10, 11041112.

147 P. Vos, M. Bučko, P. Gemeiner, M. Navrátil, J. Švitel, M. Faas, B. L. Strand, G. Skjak-Braek, Y. A. Morch, A. Vikartovská, I. Lacík, G. Kolláriková, G. Orive, D. Poncelet, J. L. Pedraz and M. B. Ansorge-Schumacher, Biomaterials, 2009, 30, 2559-2570. 
148 N. J. Zuidam and V. A. Nedović, in Encapsulation Technologies for Active Food Ingredients and Food Processing, Springer Science Business Media, 2010.

149 European Parliament, Regulation (EC) No. 1333/2008, 2008.

150 K. M. Park, H. Sung, S. J. Choi, Y. J. Choi and P. Chang, Food Chem., 2014, 161, 53-59.

151 C. Santos-Buelga, S. Gonzalez-Manzano, M. Dueñas and A. M. Gonzalez-Paramas, Natural Products Isolation, Methods in Molecular Biology, Chapter 17- Extraction and isolation of phenolic compounds, Springer Science+Business Media, 2012.

152 A. Gharsallaoui, R. Saurel, O. Chambin and A. Voilley, Food Bioprocess Technol., 2012, 5, 2211-2221.

153 U. V. L. Ma, J. D. Floros and G. R. Ziegler, Carbohydr. Polym., 2011, 83, 1869-1878.
154 E. Chan, Z. Yim, S. Phan, R. F. Mansa and P. Ravindra, Food Bioprod. Process., 2010, 88, 195-201.

155 N. Kalogeropoulos, K. Yannakopoulou, A. Gioxari, A. Chiou and D. P. Makris, LWT-Food Sci. Technol., 2010, 43, 882-889.

156 L. Tavano, R. Muzzalupo, N. Picci and B. Cindio, Colloids Surf., B, 2014, 114, 82-88.

157 L. Bagheri, A. Madadlou, M. Yarmand and M. E. Mousavi, Food Res. Int., 2014, 62, 1113-1119.

158 M. Zhao, H. Wang, B. Yang and H. Tao, Food Chem., 2010, 120, 1138-1142.

159 W. Xu, W. Jin, C. Zhang, Z. Li, L. Lin, Q. Huang, S. Ye and B. Li, Food Res. Int., 2014, 59, 61-66.

160 I. Stratulat, M. Britten, S. Salmieri, P. Fustier, D. St-Gelais, C. P. Champagne and M. Lacroix, J. Funct. Food, 2014, 6, 48-59. 